\title{
Biliary Findings on Magnetic Resonance Cholangiopancreatography in Patients with Post Cholecystectomy Pain
}

\author{
Ummara Siddique*, Syed Ghulam Ghaus, Seema Gul, Shahjehan Alam, Aman Nawaz Khan, Hadia Abid, Abdullah \\ Safi and Kalsoom Nawab
}

Department of Radiology, Rehman Medical Institute, Pakistan

Received date: December 19, 2018; Published date: January 28, 2019

*Corresponding author: Ummara Siddique, Department of Radiology, Rehman Medical Institute, Peshawar, Pakistan

\begin{abstract}
Purpose: To find the incidence of different causes of post cholecystectomy pain on magnetic resonance cholangiopancreatography.

Methodology: This is a prospective study of 74 patients with post-operative complain of post-cholecystectomy symptoms. Their ages ranged from 20 to 70 years. Patients with liver transplant were not included. MRCP was performed on 1.5 tesla GE machine at radiology department of our hospital. MRCP images were assessed for bile duct diameters and the presence of strictures and stones. A common bile duct (CBD) diameter of $<8 \mathrm{~mm}$ was considered normal, whereas $>$ or $=9 \mathrm{~mm}$ was considered abnormal. Findings were correlated with LFTs and clinical findings.
\end{abstract}

Results: Our results showed that $86.4 \%$ cases with post cholecystectomy pain had positive findings on MRCP. The commonest finding was biliary stones in $37.8 \%$ cases. Post-cholecystectomy biliary complications included retained CBD stones in 28 patients $(9$ intrahepatic, 18 extra-hepatic and 1 in cystic duct stump), biliary duct injury in 4 patients (2 cases with biliary duct ligation and 2 cases with biliary leakage. Stricture was detected in distal CBD in 9, in CHD in 4 cases, at ampulla in 2, at hilum in 9 and in 9 at anastomotic site of choledochoeneterostomy site. In 10 of our cases, MRCP was negative for any finding.

Conclusion: We conclude from our results that that $86.4 \%$ cases with post cholecystectomy pain had positive findings on MRCP and the most common cause of post cholecystectomy pain was biliary stones seen in $37.8 \%$. The use of breath-hold 3D-SSFP MRCP is essential in evaluation of post-laparoscopic cholecystectomy biliary complications and in planning for management regimens.

Recommendation: MRCP should be performed in patients with post cholecystectomy pain. If the CBD on ultrasound is $>$ or $=10 \mathrm{~mm}$ and no cause is identified, MRCP is necessary. However, the availability of LFTs raises the diagnostic value of imaging.

Keywords: Magnetic resonance cholangiopancreatography (MRCP); Biliary obstruction; Biliary stones; Calculi; Strictures

\section{Introduction}

Cholecystectomy is one of the most commonly performed operations and is mostly followed by an uneventful course [1]. Sometimes cholecystectomy fails to relieve symptoms or new symptoms develop. When the pre-surgery symptoms persist in post-op period, it is called as post-cholecystectomy syndrome (PCS), which is now a well-recognized clinical entity [2]. It is a misnomer as it is not a syndrome per se and defined as a complex of heterogeneous symptoms, consisting of upper abdominal pain and dyspepsia, which recur and/or persist after cholecystectomy [3]. PCS reportedly affects about $10-15 \%$ of patients [4]. Post cholecystectomy patients can present with recurring or persistent pain in epigastrium and upper abdomen. Study conducted by Guso and fellows in 2015 noted 25\% rate of complications in patients undergoing imaging following cholecystectomy [5].
Patients can have pain due to either biliary complication (Table 1) following surgery like retained migrated calculi, inflamed Gallbladder stump or because of operative complications like biliary leakage or ductal injury. Biliary manifestations may occur early in the post-operative period, usually because of incomplete surgery (retained calculi in the cystic duct remnant or in the common bile duct) or operative complications, such as bile duct injury and/or bile leakage. A later onset is commonly caused by inflammatory scarring strictures involving the sphincter of Oddi or the common bile duct (CBD), recurrent calculi or biliary dyskinesia. Post cholecystectomy patients can have non-hepatobiliary cause like duodenogastric reflux of bile. The overall incidence of positive endoscopic and histopathological changes in the stomach of cholecystectomized patients is 20$30 \%$ especially significant is the atrophic type of gastritis [6]. In 
another study, cholecystectomized patients when compared to cholelithiasis patients and healthy patients showed much higher duodenogastric reflux and much higher concentrations of bile acid in gastric juice [7].

Table 1: Main biliary causes of post-cholecystectomy pain / syndrome (PCS) related to cholecystectomy. (Biliary malignancies are the most frequent causes of PCS unrelated to cholecystectomy [1].

\begin{tabular}{|c|}
\hline Early Post-Op Period (Up to One Year) \\
\hline Retained stones in the cystic duct stump and/or common bile duct \\
\hline Bile duct injury/ligature during surgery \\
\hline Bile leakage \\
\hline Late Post-Op Period \\
\hline Recurrent stones in the common bile duct \\
\hline Bile duct strictures \\
\hline Cystic duct remnant harbouring stones and/or inflammation \\
\hline Gallbladder remnant harbouring stones and/or inflammation \\
\hline Papillary stenosis \\
\hline Biliary dyskinesia \\
\hline
\end{tabular}

The traditional imaging approach for diagnosing underlying cause for post cholecystectomy pain has involved ultrasound and/or Computed Tomography (CT) followed by direct cholangiography, whereas manometry of the sphincter of Oddi and biliary scintigraphy have been reserved for cases of biliary dyskinesia. Because of its capability to provide non-invasive high-quality visualization of the biliary tract, MRCP has been advocated as a reliable imaging tool for assessing patients with post cholecystectomy pain or suspected PCS and for guiding management decisions. The present study was carried out to find the incidence and risk factors for post cholecystectomy pain in patients undergoing cholecystectomy. This paper illustrates the rationale for using MRCP, together with the main MRCP biliary findings and diagnostic pitfalls.

\section{Methodology}

This is a prospective study of 74 patients with history of cholecystectomy (laparoscopic or open) and post-operative complaint of pain/post-cholecystectomy symptoms. Their ages ranged from 20 to 70 years. Patients of liver transplant were not included. MRCP was performed on 1.5 tesla GE machine at radiology department of our hospital. MRCP images were assessed for bile duct diameters and the presence of strictures and stones. Additional findings like presence of pancreatitis or fluid collections were also assessed. A common bile duct (CBD) diameter of $<8 \mathrm{~mm}$ was considered normal, whereas $>$ or $=8 \mathrm{~mm}$ was considered abnormal. Signal void foci in biliary ducts were considered as stones, whether obstructing or not. Axial T2W images were also assessed for additional related findings like presence of any neoplastic mass, pancreatitis or fluid collections etc. Findings were correlated to LFTs. For MRCP, we used sequences heavily $\mathrm{T} 2$ weighted sequences to depict the fluid-containing biliary tree and pancreatic duct. Post processing of the image data was performed to obtain maximum intensity projection (MIP) images and multiplanar reformatted images. The 3D imaging technique has potential advantages over twodimensional imaging, including the capacity to obtain thinner sections with no gap and a higher signal-to-noise ratio. Because partial volume averaging effects may obscure small stones and subtle mural irregularities, thin-section source images were always reviewed.

\section{Results}

Table 2: showing incidence of positive findings on MRCP.

\begin{tabular}{|c|c|c|}
\hline S. No. & MRCP Finding & $\begin{array}{c}\text { Incidence Total } \\
\text { Patients=74 }\end{array}$ \\
\hline 1. & Bile stones & $37.8 \%(\mathrm{n}=28)$ \\
\hline 2. & Biliary strictures & $32.4 \%(\mathrm{n}=24)$ \\
\hline 3. & Choalngitis & $14.8 \%(\mathrm{n}=11)$ \\
\hline 4. & Anastomotic strictures & $12.1 \%(\mathrm{n}=9)$ \\
\hline 5. & Pancreatitis & \\
\hline 6. & Mass at hilum & $9.4 \%(\mathrm{n}=7)$ \\
\hline 7. & GB remnant & $6.7 \%(\mathrm{n}=5)$ \\
\hline 8. & Bile duct injury & $5.4 \%(\mathrm{n}=4)$ \\
\hline 9. & $\begin{array}{c}\text { Others: PSC-4 (5.4\%) portal } \\
\text { biliopathy-2 (2.7\%) Cystic duct stump }\end{array}$ \\
\hline
\end{tabular}

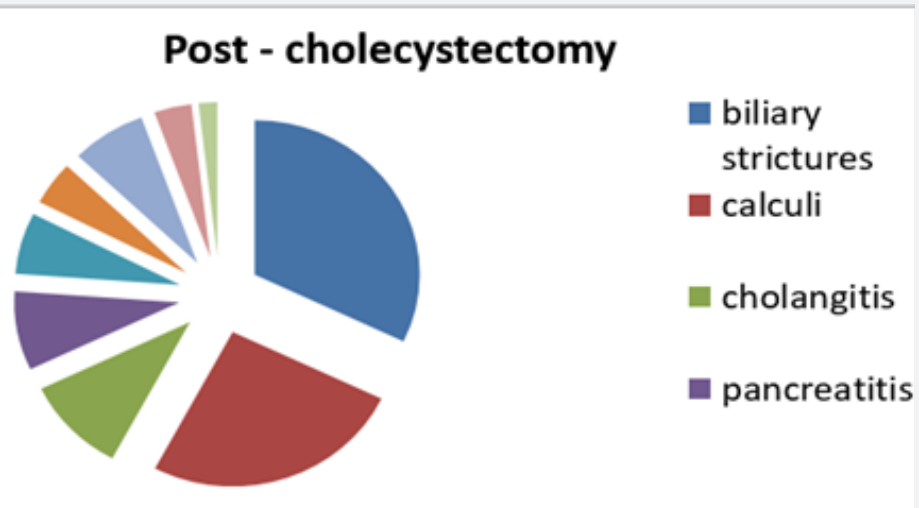

Figure 1: Incidence of MRCP findings in patients with post cholecystectomy pain. 


\section{Current Trends in Clinical \& Medical Imaging}

Table 3: showing Incidence of biliary strictures at different biliary levels.

\begin{tabular}{|c|c|c|}
\hline S. No. & Level of Biliary Stricture & Incidence \\
\hline 1. & hilar stricture & $12.10 \%$ \\
\hline 2. & CHD stricture & $5.40 \%$ \\
\hline 3. & CBD stricture & $12.10 \%$ \\
\hline 4. & Ampulla & $2.70 \%$ \\
\hline 5. & Anastomotic site stricture & $12.10 \%$ \\
\hline
\end{tabular}

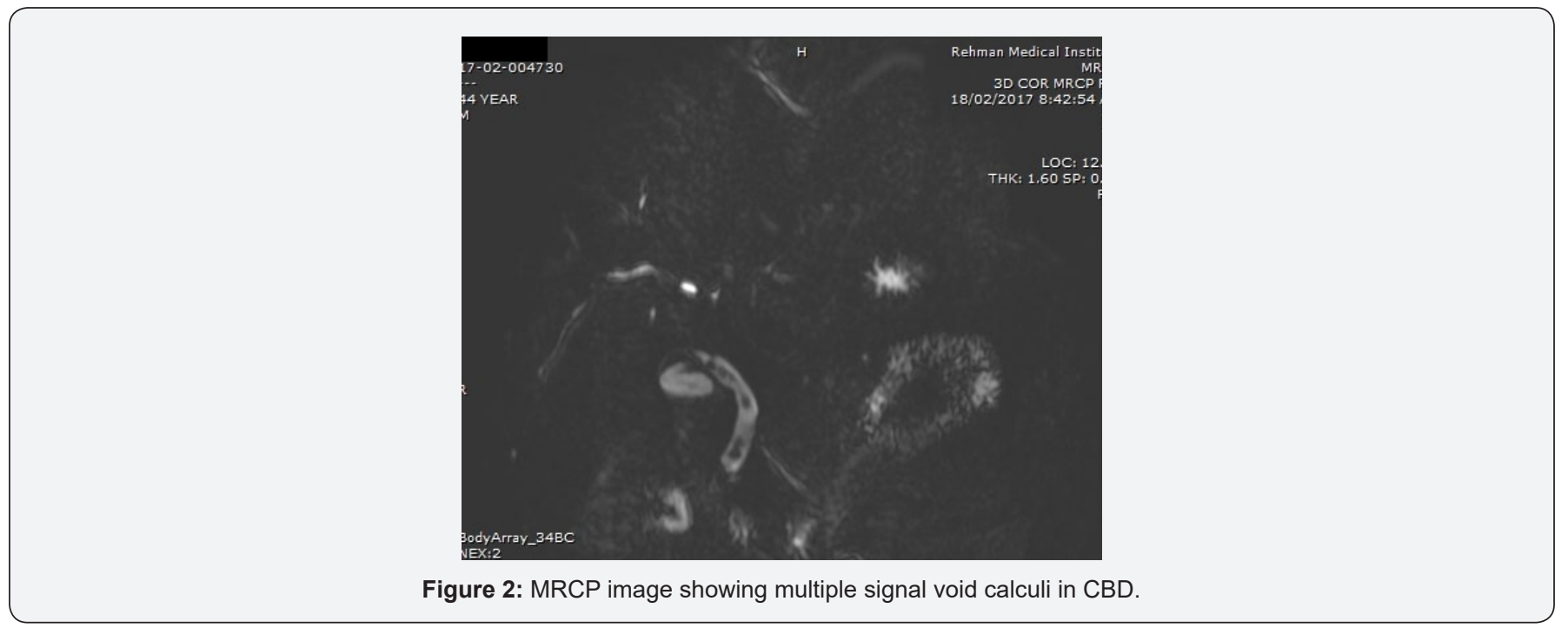

Figure 2: MRCP image showing multiple signal void calculi in CBD.

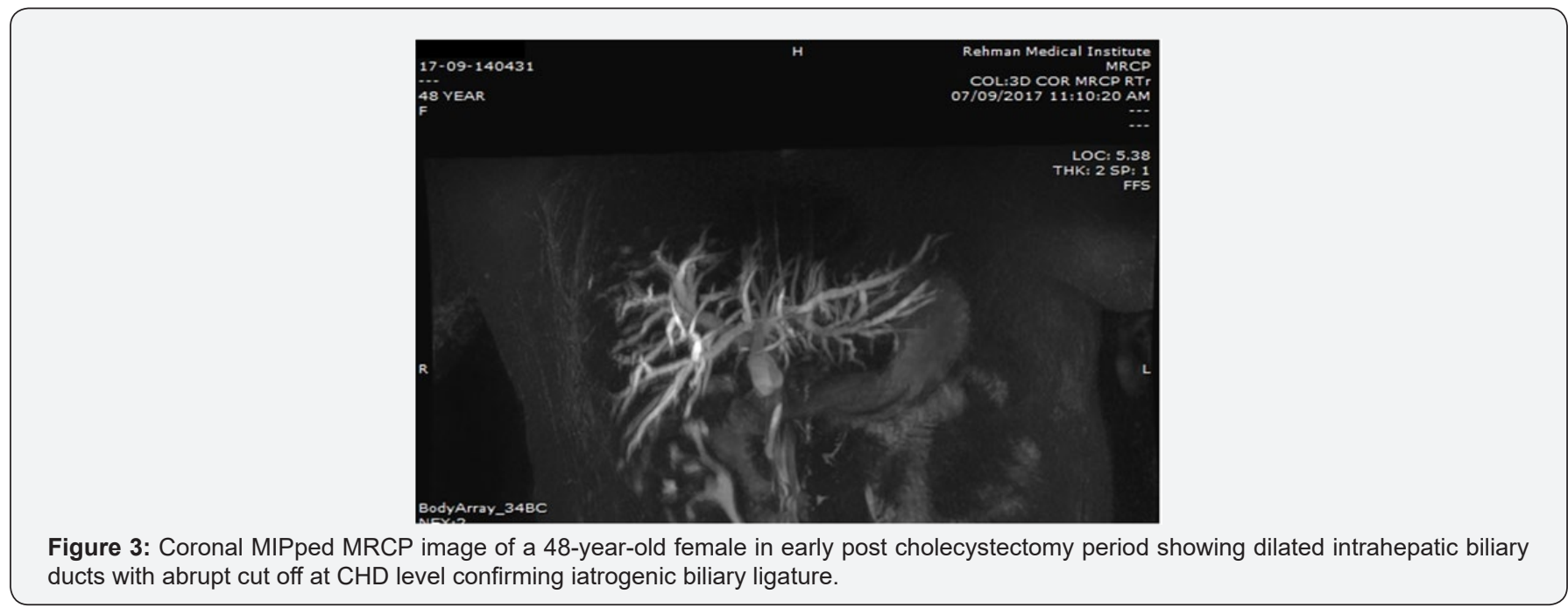

Figure 3: Coronal MIPped MRCP image of a 48-year-old female in early post cholecystectomy period showing dilated intrahepatic biliary ducts with abrupt cut off at $\mathrm{CHD}$ level confirming iatrogenic biliary ligature.

\section{Discussion}

Post cholecystectomy pain can be due to biliary and extrabiliary causes. This study focuses on biliary manifestations in patients with post cholecystectomy pain. MRCP is a non-invasive technique and beautifully highlights the biliary tree. As compared to ERCP, which is invasive and requires iodinated contrast, MRCP requires no intravenous contrast. 3D primary raw datasets are ideal for visualization of pancreatico-biliary ducts. Retained bile duct stones after cholecystectomy is a well-recognized postoperative complication. Biliary calculi are visualized as signal
Our results showed that $86.4 \%$ cases with post cholecystectomy pain had positive findings on MRCP. The commonest finding was biliary stones in $37.8 \%$ cases (Table 2 ). The commonest site of biliary stones was CBD in $24.3 \%$ cases. Biliary strictures were seen in 33 patients (in distal CBD in 9, in CHD in 4 cases, at ampulla in 2, at hilum in 9 and in 9 at anastomotic site of choledochoeneterostomy site) (Table 3) (Figures 1-6). GB remnant was seen in 5, one of which had stones. Other findings included biliary leak, duct injury, PSC, portal biliopathy, cholangitis and hilar mass. In 10 of our cases, MRCP was negative for any finding. Pancreatitis was seen in 9 patients.

void foci within the T2 hyperintense bile. The reported incidence after laporoscopic cholecystectomy is $0.5-2 \%$ and after open cholecystectomy, it varies between 5-15\% [8]. A study conducted in Pakistan showed that the most common etiological diagnostic finding was residual biliary stones; followed by iatrogenic bile duct obstruction [9]. A large proportion of MRCP findings in our study also had retained biliary calculi i.e $37.8 \%(n=28)$.

Solitary CBD stones were detected in 18 cases, which is comparable to study conducted by Durrani and fellows, which showed 15 cases with isolated CBD stones. Their study showed 


\section{Current Trends in Clinical \& Medical Imaging}

$39 \%$ cases 8 with retained biliary calculi whereas our study showed $37.8 \%$, which is comparable. In their study calculi in both intrahepatic ducts were seen in 13 cases, whereas in our study intrahepatic duct stones were seen in 9. In our study retained CBD calculi accounted for $24.3 \% \%$ of the complications whereas in a study conducted by Ganci-Cerrud, it was 17\% [10]. For suspected biliary duct stones, ERCP followed by sphincterotomy and caluli extraction is the preferred initial approach, if the probability is high $[1,4,7]$.

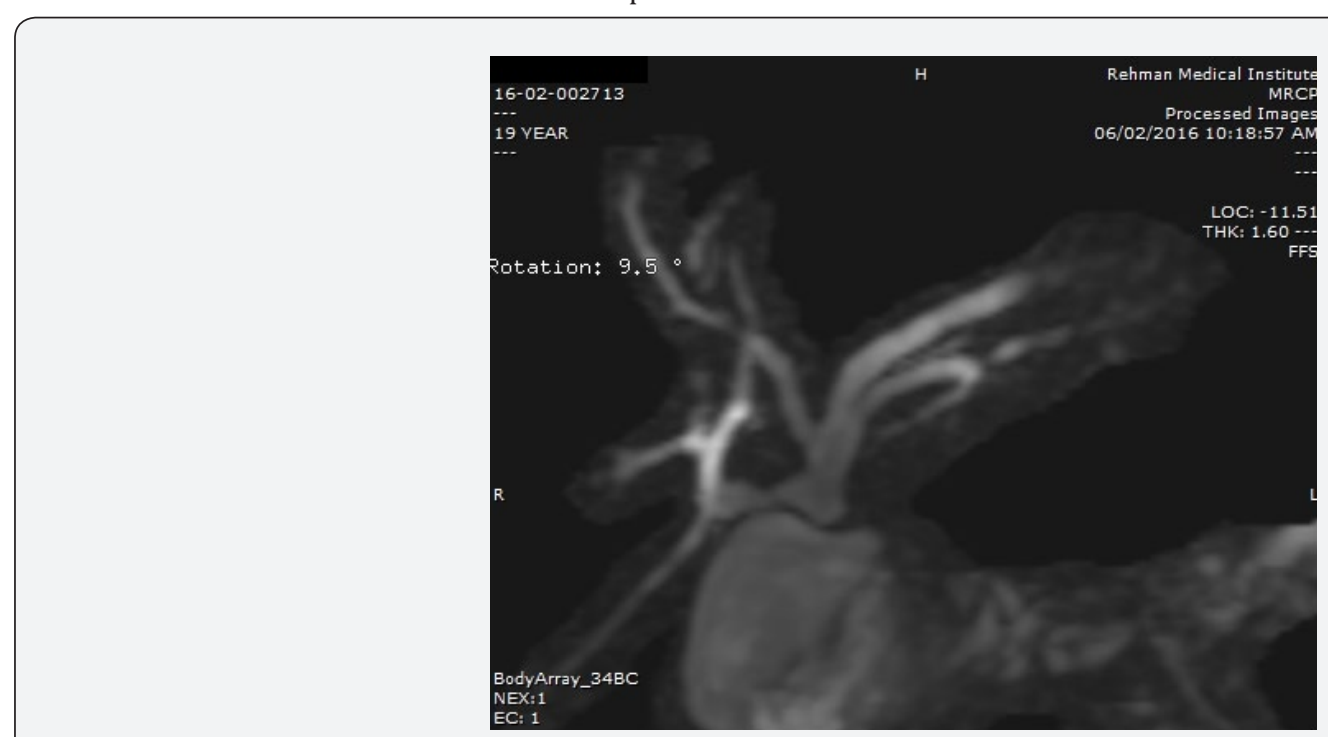

Figure 4: MRCP image showing anastomotic site stricture.

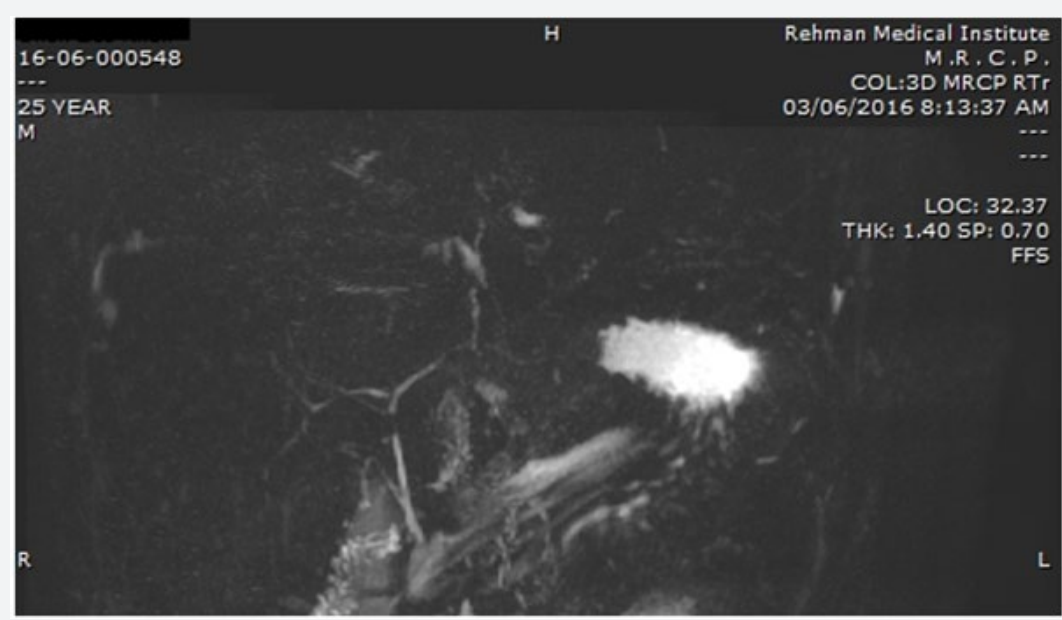

Figure 5: MRCP image showing PSC. There is paucity of biliary ducts. Multiple strictures seen in intrahepatic ducts and in proximal CHD without biliary dilatation.

Stones smaller than $3 \mathrm{~mm}$ can pass spontaneously if the sphincter of oddi is not stenotic, which, may be complicated by pancreatitis or cholangitis. In our study, pancreatitis was seen in 9 and cholangitis in 11 of our cases, the causes might be the same. In our study the most common finding overall was strictures, commonest site being the CBD, CHD and hilum. In study conducted by Duran [9] and fellows, the second most common complication was iatrogenic ligature in $13 \%$ patients, whereas in our study the iatrogenic bile duct injury was seen in only $5.4 \%$ cases. Their study had 8 cases with post-operative CBD stricture, whereas in our study CBD strictures were seen in 9 which is comparable. These CBD strictures can be managed by endoscopic stenting and so ERCP was suggested.
Our results showed that $86.4 \%$ cases with post cholecystectomy pain had positive findings on MRCP. It was noted in our patients that the commonest site of biliary stones was $\mathrm{CBD}$, biliary strictures were commonly in distal CBD, confluence and anastomotic site. Another finding seen was documented as the GB remnant, seen in 5 of our cases, one of which had stones. This GB remnant coud be either a duplicate gallbladder, dilated cystic duct stump or partially left GB in cases of partial cholecystectomy. The surgical details could not be obtained as most of the patients were referred from other centers.

Biliary dilatation cannot be the only presentation of biliary pathologies. Primary sclerosing cholangitis (PSC) is an entity 


\section{Current Trends in Clinical \& Medical Imaging}

with multiple small biliary strictures without any significant biliary dilatation. Findings of PSC were seen in 4 of our cases. Two of our patients with post cholecystectomy pain had biliary dilatation due to portal biliopathy. Mass at hilum was diagnosed in 7 of our cases, which were advised cytological brushings and biopsy. Post cholecystectomy pain can be due to a number of reasons and commonest in our study was biliary calculi. The preoperative incidence of choledocolithiasis amongst patients undergoing cholecystectomy is reported to be $10-15 \%$ [11]. However, the retention of CBD calculi after open cholecystectomy is between $5-15 \% 10$. MRCP can identify stones as small as $2 \mathrm{~mm}$ that are retained in the biliary tree [12].

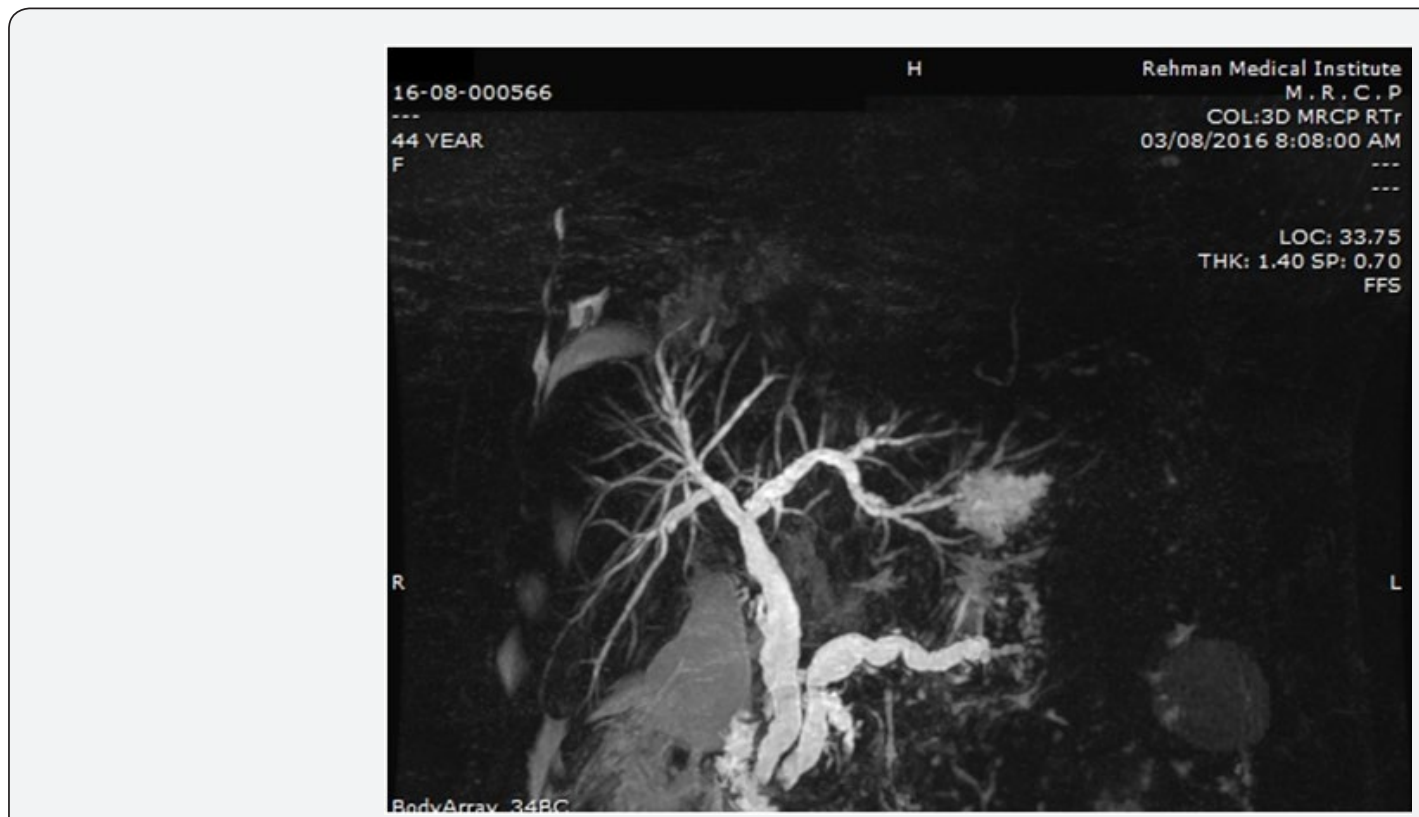

Figure 6: MRCP image showing a signal void filling defect at ampulla causing upstream dilatation of biliary and pancreatic ducts. Differentials in this case includes obstructed calculus and ampullary mass.

\section{References}

1. Ketan V, Amish P, Suvarna V, Shamshershah P, Rohini D (2016) Post cholecystectomy pancreatitis: a misleading entity. Int Surg J 3(2): 941943.

2. Arora D, Kaushik R, Kaur R, Sachdev A (2017) Post -cholecystectomy syndrome: A new look at an old problem. J Minim Access Surg 23.

3. Fatin RP, Yasin D (2018) "Postcholecystectomy Syndrome and Cholangiography”. EC Gastroenterology and Digestive System 5(1): 17 18.

4. Girometti R, Brondani G, Cereser L, Como G, Del Pin M, et al. (2010) Post-cholecystectomy syndrome: spectrum of biliary findings at magnetic resonance cholangiopancreatography. Br J Radiol 83(988): 351-361.

5. Gorsi U, Gupta P, Kalra N, Kang M, Singh R, et al. (2015) Multidetector computed tomography evaluation of post cholecystectomy complications: A tertiary care center experience. Trop Gastroenterol 36(4): 236-243.

6. Nudo R, Pasta V, Monti M, Vergine M, Picardi N (1989) Correlation between Postcholecystectomy syndrome and biliary reflux gastritis. Endoscopic study. Ann Ital Chir 60(4): 291-300.
7. Koelsch KA, Kuhne C, Zemlin C (1979) Postcholecystecomy condition: duodenogastric reflux and bile acid concentration in the gastric juice. Z-Gesamte-Inn-Med 34(13): 361-364.

8. Rogers AL, Fraha GJ, Beamer RL, Chang FC (1985) Incidence and associated mortality of retained common bile duct stones. Am J Surg 150(6): 690-693.

9. Durrani AA, Yaqoob N, Hussan Z, Siddique M, Moin S, et al. (2007) Postcholecystectomy complications and ERCP. Pak J Med Sci 23 (4): 614661.

10. Ganci-Cerrud G, Chan C, Bobadilla J, Elizondo J, Valdovinos MA, et al. (2001) Management of choledocholithiasis found during laparoscopic cholecystectomy: a strategy based on the use of postoperative endoscopic retrograde cholangiography and sphincterotomy. Rev Invest Clin 53(1): 17-20.

11. Martin DJ, Vernon DR, Toouli J (2006) Surgical versus endoscopic treatment of bile duct stones. Cochrane Database Syst Rev 19 (2): CD 003327.

12. Hallal AH, Amortegui JD, Jeroukhimov IM (2005) Magnetic resonance cholangiopancreatography accurately detects common bile duct stones in resolving gallstone pancreatitis. J Am Coll Surg 200(6): 869-875. 


\section{Current Trends in Clinical \& Medical Imaging}

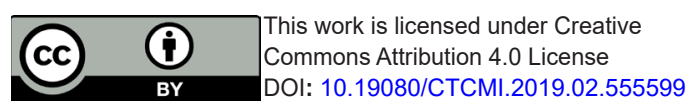

\section{Your next submission with Juniper Publishers} will reach you the below assets

- Quality Editorial service

- Swift Peer Review

- Reprints availability

- E-prints Service

- Manuscript Podcast for convenient understanding

- Global attainment for your research

- Manuscript accessibility in different formats

( Pdf, E-pub, Full Text, Audio)

- Unceasing customer service

Track the below URL for one-step submission https://juniperpublishers.com/online-submission.php 